\title{
Kinetics and Mechanism of Keggin Type 12-Tungstocobaltate(II) Catalyzed Oxidation of Hexacyanoferrate(II) by Perborate
}

\author{
D. S. RAJMANE ${ }^{*}$ and G. S. GOKAVI ${ }^{2}$ \\ ${ }^{1}$ Department of Chemistry, Shrimant Babasaheb Deshmukh Mahavidyalaya, \\ Atpadi-415301, India \\ ${ }^{2}$ Kinetics and Catalysis Research Laboratory, Department of Chemistry, \\ Shivaji University, Kolhapur, India \\ rajmaneds@gmail.com
}

Received 30 June 2014 / Accepted 26 July 2014

\begin{abstract}
The oxidation of hexacyanoferrate(II) by perborate catalyzed by Keggin type $\left[\mathrm{Co}^{\mathrm{II}} \mathrm{W}_{12} \mathrm{O}_{40}\right]^{6-}$ has been studied in sulphuric acid medium. The reaction proceeds by the oxidation of $\left[\mathrm{Co}^{\mathrm{II}} \mathrm{W}_{12} \mathrm{O}_{40}\right]^{6-}$ to $\left[\mathrm{Co}^{\mathrm{III}} \mathrm{W}_{12} \mathrm{O}_{40}\right]^{5-}$ by hydrogen peroxide, generated by the decomposition of perborate, which then oxidizes hexacyanoferrate(II) to hexacyanoferrate(III) in a rate determining step. The reaction was found to be inhibited by increase in the $\left[\mathrm{H}^{+}\right]$due to conversion of active hexacyanoferrate(II) into an inactive protonated form. Decreasing the relative permittivity of the medium increases the rate of the reaction which is attributed to the formation of an outer-sphere complex between the catalyst and active oxidant. The activation parameters were also determined and the values support the proposed mechanism.
\end{abstract}

Keywords: Kinetics, Mechanism, Hexacyanoferrate(II) oxidation, Perborate

\section{Introduction}

Heteropoly oxometalates ${ }^{1}$ are very good candidates for homogeneous outer-sphere electron transfer processes. These are also used extensively as model systems for fundamental research providing unique opportunities for mechanistic studies on molecular level. Transition metal substituted heteropoly oxometalates exhibit different chemical and electrochemical properties, which makes them attractive for catalytic ${ }^{1-4}$ and electrocatalytic ${ }^{5}$ applications.

Sodium perborate is widely used industrial chemical, mainly as a bleaching agent ${ }^{6}$ with the empirical formula $\mathrm{NaBO}_{3} \cdot \mathrm{xH}_{2} \mathrm{O}$. It is also a very convenient source of hydrogen peroxide in solution and is less expensive, solid and easily handled mild oxidizing agent which has been used for various organic functional group transformations ${ }^{6}$. The rates of oxidations by perborate are generally slow at normal temperatures thus requiring the presence 
of catalysts. Various metal ion catalysts have been reported for the perborate oxidations, normally involving formation of a peroxometal intermediate ${ }^{7-10}$ which then effects the oxidation of the substrate. Utilization of the polyoxometalates, as redox catalysts, in perborate oxidations may involve an outer-sphere path way without formation of a peroxometal intermediate. Therefore, in continuation of our earlier work ${ }^{3,4}$ on the catalysis by polyoxometalates, herein we report the 12-tungstocobaltate(II) catalyzed oxidation of hexacyanoferrate(II) by perborate.

\section{Experimental}

Reagent grade chemicals and doubly distilled $\mathrm{H}_{2} \mathrm{O}$ were used throughout. The cobalt complexes $\left[\mathrm{Co}^{\mathrm{II}} \mathrm{W}_{12} \mathrm{O}_{40}\right]^{6-}$ was prepared by literature method ${ }^{11,12}$ and standardized spectrophotometrically ${ }^{13}$ (at $624 \mathrm{~nm}$ for $\left[\mathrm{Co}^{\mathrm{II}} \mathrm{W}_{12} \mathrm{O}_{40}\right]^{6-}$ ) using an Elico SL $159 \mathrm{UV}-\mathrm{Vis}$ spectrophotometer. The solutions of perborate (Lancaster) were freshly prepared and standardized iodometrically. The ionic strength was maintained using $\mathrm{NaClO}_{4}$ and in order to vary hydrogen ion concentration, $\mathrm{H}_{2} \mathrm{SO}_{4}(\mathrm{BDH})$ was used. The solutions of hexacyanoferrate(II) and hexacyanoferrate(III)( $\mathrm{BDH})$ were prepared in water and their concentrations were ascertained by titrating against standard ceric ammonium sulphate and iodometrically respectively.

\section{Kinetic procedure}

The reactions were studied under second-order conditions by following the absorbance of hexacyanoferrate(III) at $420 \mathrm{~nm}\left(\varepsilon=1040 \pm 10 \mathrm{dm}^{3} \mathrm{~mol}^{-1} \mathrm{~cm}^{-1}\right)$ rate constants were obtained from linear $(\mathrm{r}>0.966) \log [\mathrm{a}(\mathrm{b}-\mathrm{x}) / \mathrm{b}(\mathrm{a}-\mathrm{x} / 2)]$ or $1 /(\mathrm{b}-\mathrm{x})$ (for equinormal concentrations of reactants) against time plots where $\mathrm{a}$ and $\mathrm{b}$ are concentrations of oxidant and reductant respectively. The rate constants were reproducible to within $\pm 4 \%$.

\section{Stoichiometry}

The stoichiometry of the reaction between perborate and hexacyanoferrate(II) in presence of 1.0 $\times 10^{-5} \mathrm{~mol} \mathrm{dm}^{-3}\left[\mathrm{Co}^{\mathrm{II}} \mathrm{W}_{12} \mathrm{O}_{40}\right]^{6-}$ was studied by keeping the concentration of hexacyanoferrate(II) $\left(4.0 \times 10^{-4} \mathrm{~mol} \mathrm{dm}^{-3}\right)$ constant and varying the perborate concentration from 0.5 to $1.5 \times 10^{-4} \mathrm{~mol}$ $\mathrm{dm}^{-3}$ in $1.0 \times 10^{-3} \mathrm{~mol} \mathrm{dm}^{-3} \mathrm{H}_{2} \mathrm{SO}_{4}$. The reactants were mixed and the concentration of hexacyanoferrate(III) was determined spectrophotometrically after $24 \mathrm{~h}$ at $420 \mathrm{~nm}$. The stoichiometry was found to be 2 moles of hexacyanoferrate(II) per mole of perborate.

\section{Results and Discussion}

Uncatalyzed oxidation of the hexacyanoferrate(II) by perborate did not occur under the experimental conditions. Therefore, there was no contribution of the uncatalyzed reaction to the overall rate constant of the reaction. The second-order rate constants of the reaction (Table 1) remain unchanged as both the reactant concentrations are varied at a constant concentration of catalyst $\left[\mathrm{Co}^{\mathrm{II}} \mathrm{W}_{12} \mathrm{O}_{40}\right]^{6-}\left(1.0 \times 10^{-5} \mathrm{~mol} \mathrm{dm}^{-3}\right)$ indicating overall second order nature of the reaction. Where as the second-order rate constants increase with increase in concentration of the catalyst (Figure 1) indicating the order in catalyst to be unity. The increasing $\left[\mathrm{H}^{+}\right]$decreases the values of second order rate constant with a fractional negative order. There was no effect of the added product hexacyanoferrate(III) on the reaction. The effect of ionic strength and solvent polarity on the reaction was studied by varying the concentration of sodium perchlorate $\left(0.1\right.$ to $\left.0.5 \mathrm{~mol} \mathrm{dm}^{-3}\right)$ and acetonitrile $(0-50 \% \mathrm{v} / \mathrm{v})$. There was no effect of ionic strength on the reaction where as the decrease in the dielectric constant increases the rate of the reaction. 
Table 1. Effect of reactants on the perborate oxidation of hexacyanoferrate(II) catalyzed by 12-tungstocobaltate(II) at $30{ }^{\circ} \mathrm{C} .\left[\mathrm{H}_{2} \mathrm{SO}_{4}\right]=1.0 \times 10^{-2} \mathrm{~mol} \mathrm{dm}^{-3},\left[\mathrm{Co}^{\mathrm{II}} \mathrm{W}_{12} \mathrm{O}_{40}\right]^{5-}=1.0 \times 10^{-5}$ $\mathrm{mol} \mathrm{dm}{ }^{-3}, \mathrm{I}=0.1 \mathrm{~mol} \mathrm{dm}^{-3}$

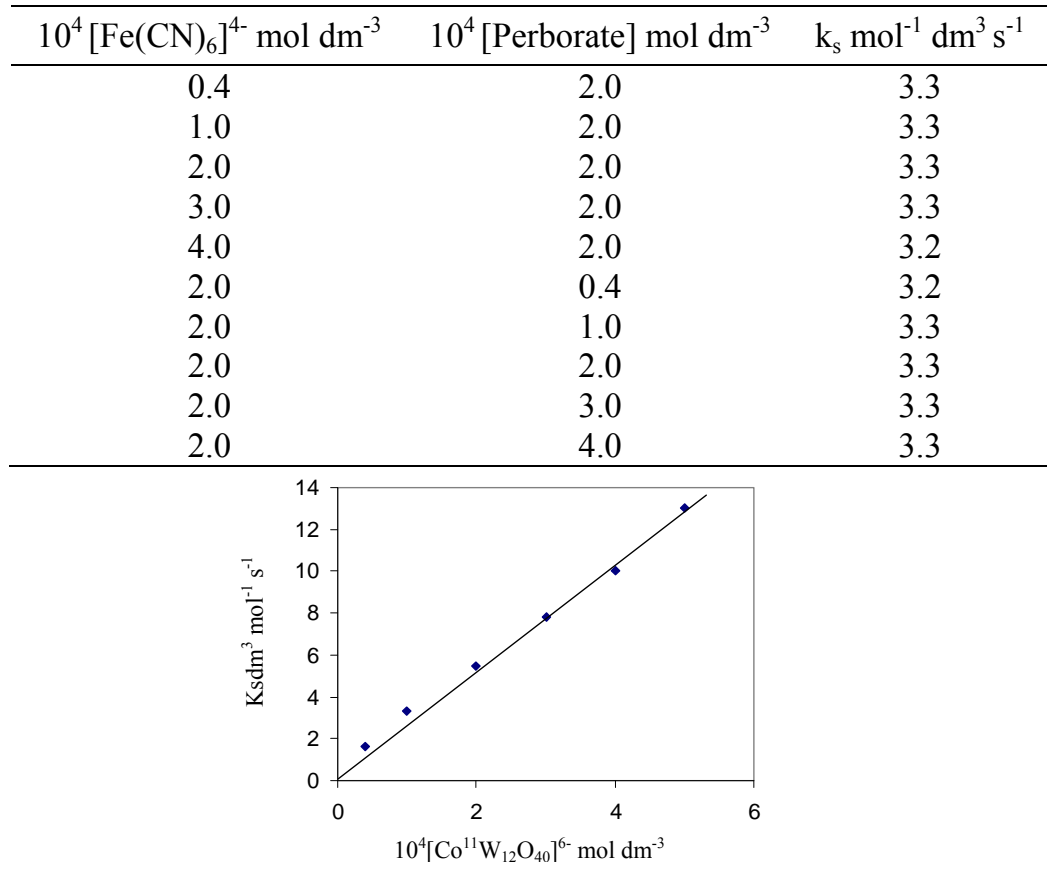

Figure 1. Effect of catalyst concentration on the perborate oxidation of hexacyanoferrate(II) catalyzed by 12 -tungstocobaltate(II) at $30{ }^{\circ} \mathrm{C}$. $[$ Perborate $]=\left[\mathrm{Fe}(\mathrm{CN})_{6}\right]^{4-}=2.0 \times 10^{-4} \mathrm{~mol} \mathrm{dm}^{-3}$, $\left[\mathrm{H}_{2} \mathrm{SO}_{4}\right]=1.0 \times 10^{-2} \mathrm{~mol} \mathrm{dm}^{-3}, \mathrm{I}=0.1 \mathrm{~mol} \mathrm{dm}^{-3}$

The effect of temperature was studied at 20, 25, 30 and $35{ }^{\circ} \mathrm{C}$ and the activation parameters for $\left[\mathrm{Co}^{\mathrm{II}} \mathrm{W}_{12} \mathrm{O}_{40}\right]^{6-}$ catalyzed hexacyanoferrate(II) oxidation by perborate were calculated as $\Delta \mathrm{H}^{\#}=32.92 \pm 6 \mathrm{~kJ} \mathrm{~mol}^{-1}, \Delta \mathrm{G}^{\#}=69.24 \pm 5 \mathrm{~kJ} \mathrm{~mol}^{-1}$ and $\Delta \mathrm{S}^{\#}=-121.8 \pm 8 \mathrm{~J} \mathrm{~K}^{-1} \mathrm{~mol}^{-1}$.

Perborate in aqueous solutions is known to generate hydrogen peroxide which is the active oxidant. Depending upon the metal ion catalyst used various mechanisms have been proposed $^{14}$ for the oxidations by peroxides. A radical mechanism via a redox reaction between metallic ion and peroxide, an ionic mechanism via formation of metallic peroxide or metal-peroxide complexes or via formation of peroxide-Lewis acid complex are the main features of the different pathways for peroxide oxidations. Since the uncatalyzed reaction does not occur to any significant extent under the present reaction conditions the reaction is initiated by the interaction between the catalyst and the hydrogen peroxide generated in solution. The catalyst used is a polyoxometalate $\left(\left[\mathrm{Co}^{\mathrm{II}} \mathrm{W}_{12} \mathrm{O}_{40}\right]^{6-}\right)$ known to be an outersphere reagent which preferably gets oxidized by the hydrogen peroxide to $\left[\mathrm{Co}^{\mathrm{III}} \mathrm{W}_{12} \mathrm{O}_{40}\right]^{5-}$ and also generating hydroxyl free radical. The oxidized form of the catalyst then reacts with the reductant in the subsequent step to give products.

The inhibiting effect of hydrogen ion concentration on the rate of the reaction is due to the participation of protonation equilibria in the mechanism. The order in hydrogen ion concentration was found to be negative and less than unity and the plot of $1 / \mathrm{k}_{\mathrm{s}}$ against $\left[\mathrm{H}^{+}\right]$ (Figure 2) was also found to be linear with an intercept. Such an inhibiting effect of $\left[\mathrm{H}^{+}\right]$on 
the reaction indicate involvement of only one protonation prior equilibria and the unprotonated form of the reactant is an active species. In the present study the variation of $\left[\mathrm{H}^{+}\right]$in the solution was carried out by using sulphuric acid, a dibasic acid, which is known to dissociate in two successive equilibrium out of which the first one can be taken as complete in moderately dilute solutions and second dissociation constant is reported to be $0.012 \mathrm{~mol} \mathrm{dm}^{-3}$. The concentrations of $\left[\mathrm{H}^{+}\right],\left[\mathrm{HSO}_{4}^{-}\right]$and $\left[\mathrm{SO}_{4}{ }^{2-}\right]$ were calculated (Table 2$)$ and the actual $\left[\mathrm{H}^{+}\right]$was used to analyse the results obtained. In acidic solutions $\mathrm{Fe}(\mathrm{CN})_{6}{ }^{4-}$ undergo protonation ${ }^{15}$ with the equilibrium constant $1470 \mathrm{~mol}^{-1} \mathrm{dm}^{3}$ and the catalyst do not undergo protonation ${ }^{3,4}$ therefore, under the reaction conditions, the concentration of protonated and unprotonated $\mathrm{Fe}(\mathrm{CN})_{6}{ }^{4-}$ were calculated (Table 2). Since, as mentioned earlier, the unprotonated $\mathrm{Fe}(\mathrm{CN})_{6}{ }^{4-}$ is the active species of the reductant a comparison of concentration of free $\mathrm{Fe}(\mathrm{CN})_{6}^{4-}$ and rate constant as a function of $\left[\mathrm{H}^{+}\right]$was made graphically (Figure 3). From the Figure 3 it was found that the rate constant of the reaction varies with the $\left[\mathrm{H}^{+}\right]$parallel to the $\left[\mathrm{Fe}(\mathrm{CN})_{6}{ }^{4-}\right]$ thus indicating it as the reactive species. The mechanism in terms of the reactive species can now be represented by Scheme 1 with the corresponding rate law and the second order rate constant, at constant catalyst concentration, by equations 1 and 2 respectively.

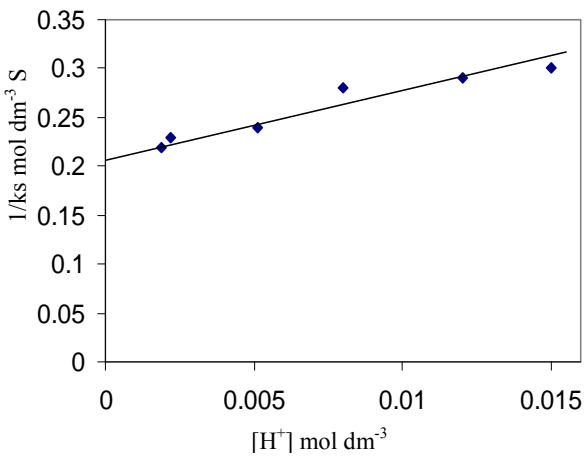

Figure 2. Plot of $1 / \mathrm{k}_{\mathrm{s}}$ against $\left[\mathrm{H}^{+}\right]$(Conditions as in Table 2)

Table 2. Effect of hydrogen ion concentration on the perborate oxidation of Hexacyanoferrate(II) catalyzed by 12 -tungstocobaltate(II) at $30{ }^{\circ} \mathrm{C}$. [Perborate $]=\left[\mathrm{Fe}(\mathrm{CN})_{6}\right.$ ]$^{4-}=2.0 \times 10^{-4} \mathrm{~mol} \mathrm{dm}^{-3},\left[\mathrm{Co}^{\mathrm{II}} \mathrm{W}_{12} \mathrm{O}_{40}\right]^{5-}=1.0 \times 10^{-5} \mathrm{~mol} \mathrm{dm}^{-3} . \mathrm{I}=0.1 \mathrm{~mol} \mathrm{dm}^{-3}$

\begin{tabular}{|c|c|c|c|c|}
\hline $\begin{array}{l}10^{2}\left[\mathrm{H}_{2} \mathrm{SO}_{4}\right] \\
\mathrm{mol} \mathrm{dm}^{-3} \mathrm{~s}^{-1}\end{array}$ & $\begin{array}{l}10^{2}\left[\mathrm{H}^{+}\right] \\
\mathrm{mol} \mathrm{dm}\end{array}$ & $\begin{array}{c}10^{5}\left[\mathrm{Fe}(\mathrm{CN})_{6}\right]^{4-} \\
\mathrm{mol} \mathrm{dm}^{-3}\end{array}$ & $\begin{array}{c}10^{-4}\left[\mathrm{HFe}(\mathrm{CN})_{6}\right]^{3-} \\
\mathrm{mol} \mathrm{dm}^{-3}\end{array}$ & $\begin{array}{c}\mathrm{k}_{\mathrm{s}} \\
\mathrm{mol}^{-1} \mathrm{dm}^{3}\end{array}$ \\
\hline 0.1 & 0.19 & 5.3 & 1.47 & 4.6 \\
\hline 0.2 & 0.35 & 3.3 & 1.67 & 4.4 \\
\hline 0.3 & 0.51 & 2.4 & 1.76 & 4.1 \\
\hline 0.5 & 0.80 & 1.6 & 1.80 & 3.6 \\
\hline 0.8 & 1.2 & 1.1 & 1.9 & 3.4 \\
\hline 1.0 & 1.5 & 0.9 & 1.9 & 3.3 \\
\hline \multicolumn{5}{|c|}{ Rate $=\frac{\mathrm{k}\left[\mathrm{Co}^{11} \mathrm{~W}^{12} \mathrm{O}_{40}\right]^{6-}\left[\mathrm{Fe}(\mathrm{CN})_{6}\right]^{4-}\left[\mathrm{H}_{2} \mathrm{O}_{2}\right]}{1+\mathrm{K}\left[\mathrm{H}^{+}\right]}$} \\
\hline
\end{tabular}




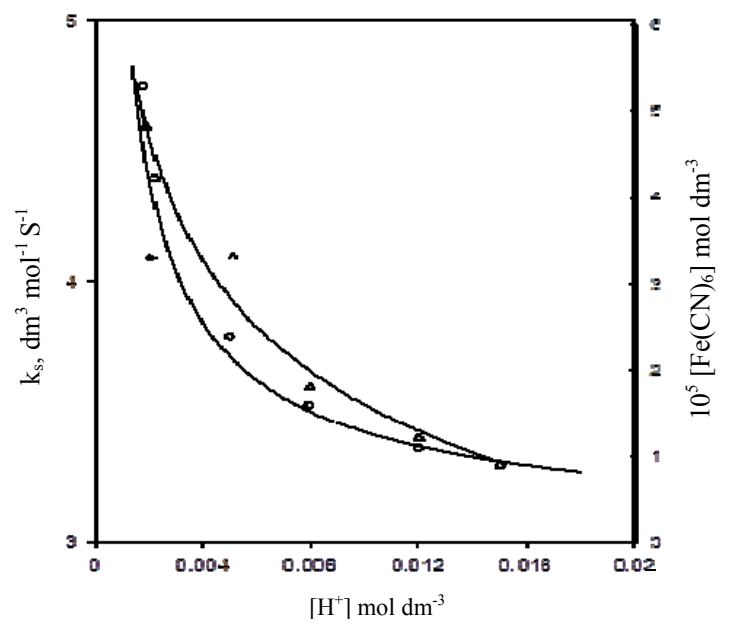

Figure 3. Plot of $\mathrm{k}_{\mathrm{s}}(\Delta)$ and $\left[\mathrm{Fe}(\mathrm{CN})_{6}\right]^{4-}(\mathrm{o})$ against $\left[\mathrm{H}^{+}\right]$(Conditions as in Table 2)

The mechanism in the Scheme 1 occurs with rate determining oxidation of the catalyst $\left[\mathrm{Co}^{\mathrm{II}} \mathrm{W}_{12} \mathrm{O}_{40}\right]^{5-}$ to $\left[\mathrm{Co}^{\mathrm{III}} \mathrm{W}_{12} \mathrm{O}_{40}\right]^{6-}$ generating hydroxyl free radical. Both hydroxyl free radical and $\left[\mathrm{Co}^{\mathrm{III}} \mathrm{W}_{12} \mathrm{O}_{40}\right]^{6-}$ will oxidize the reductant in the following steps. The ionic strength did not affect the rate of the reaction as the reaction initiation involves a neutral $\mathrm{H}_{2} \mathrm{O}_{2}$ species. According to equation 2 a plot of $1 / \mathrm{k}_{\mathrm{s}}$ against $\left[\mathrm{H}^{+}\right]$is expected to be linear and found to be so (Figure 2). A decrease in entropy of the reaction may be attributed to the transition state formed between the catalyst and the oxidant. The catalyst is an outer sphere reagent and the transition state is probably replacement of one of its hydrated water molecule by the oxidant. The transition state is less solvated and is more stabilized in a medium of low relative permittivity.

$$
\begin{aligned}
\mathrm{H}^{+}+\left[\mathrm{Fe}(\mathrm{CN})_{6}\right]^{4-} & \stackrel{\mathrm{K}}{\longrightarrow} \mathrm{H}\left[\mathrm{Fe}(\mathrm{CN})_{6}\right]^{3-} \\
\mathrm{H}_{2} \mathrm{O}_{2}+\left[\mathrm{Co}^{\prime \prime} \mathrm{W}_{12} \mathrm{O}_{40}\right]^{6-} & \stackrel{\mathrm{k}}{\longrightarrow} \mathrm{HO}+\mathrm{OH}^{-}+\left[\mathrm{Co}^{\prime \prime \prime} \mathrm{W}_{12} \mathrm{O}_{40}\right]^{5-} \\
{\left[\mathrm{Co}^{\prime \prime \prime} \mathrm{W}_{12} \mathrm{O}_{40}\right]^{5-}+\left[\mathrm{Fe}(\mathrm{CN})_{6}\right]^{4-} } & \stackrel{\text { fast }}{\longrightarrow}\left[\mathrm{Co}^{\prime \prime} \mathrm{W}_{12} \mathrm{O}_{40}\right]^{6-}+\left[\mathrm{Fe}(\mathrm{CN})_{6}\right]^{3-} \\
{\left[\mathrm{Fe}(\mathrm{CN})_{6}\right]^{4-}+\mathrm{HO} } & \stackrel{\text { fast }}{\longrightarrow}\left[\mathrm{Fe}(\mathrm{CN})_{6}\right]^{3-}+\mathrm{OH}^{-} \\
2 \mathrm{OH}^{-}+2 \mathrm{H}^{+} & \stackrel{\text { fast }}{\longrightarrow} 2 \mathrm{H}_{2} \mathrm{O}
\end{aligned}
$$

\section{References}

Scheme 1. The reaction mechanism

1. Weinstock I A, Chem Rev., 1998, 98(1), 113-170; DOI:10.1021/cr9703414

2. Mardur S P, Halligudi S B and Gokavi G S, Catal Lett., 2004, 96(3-4),165-167; DOI:10.1023/B:CATL.0000030115.24111.5c

3. Rajmane D S and Gokavi G S, Int J Chem Sci., 2014, 12(1), 145-154.

4. Rajmane D S, Kapashikar K V and Gokavi G S, Indian J Chem., 2006, 45A, 1626-1630.

5. Sadakane M and Steckhan E, Chem Rev., 1998, 98(1), 219-238;

DOI:10.1021/cr960403a 
6. Safaiee M, Synlett, 2006, 15, 2513-2514; DOI:10.1055/s-2006-949628

7. Karunakaran C and Venkataraman R, Cat Commun., 2006, 7(4), 236-239; DOI:10.1016/j.catcom.2005.09.016

8. Karunakaran C, Ramachandran V and Palanisamy P N, Eur J Org Chem., 2000, 2000(19), 3261-3263;

DOI:10.1002/1099-0690(200010)2000:19<3261::AID-EJOC3261>3.0.CO;2-U

9. Karunakaran C and Kamalan R, Synth React Inorg Metal-Org Chem., 1999, 29(8), 1463-1474; DOI:10.1080/00945719909351711

10. Karunakaranand C and Muthukumar B, Polish J Chem., 1999, 73(11), 1827-1836.

11. Baker L C W and McCutcheon T P, J Am Chem Soc., 1956, 78(18), 4503-4510; DOI:10.1021/ja01599a001

12. Rasmussen P G and Jr Brubaker C H, Inorg Chem., 1964, 3(7), 977-980; DOI:10.1021/ic50017a011

13. Goyal B, Prakash A and Mehrotra R N, Indian J. Chem., 1999, 38A, 541-546.

14. Ogata Y and Sawaki Y, Organic Syntthesis by Oxidation with Metal Compounds, Mijs W J and De Jonge C R H I, Eds., (Plenum Press, New York, 1986, 839-876.

15. Rabai $\mathrm{G}$ and Epstein I R, Inorg Chem., 1989, 28(4), 732-736; DOI:10.1021/ic00303a024 